\title{
Prevalence of pulmonary embolism on hospital admission in COVID-19 patients: is there a role for pre-test probability scores and home treatment?
}

\begin{abstract}
To the Editor:
Copyright @The authors 2021

This version is distributed under the terms of the Creative Commons Attribution Non-Commercial Licence 4.0. For commercial reproduction rights and permissions contact permissions@ersnet.org

Received: 16 March 2021 Accepted: 26 March 2021

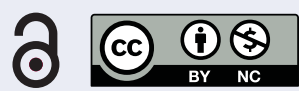

We read with interest the research letter recently authored by JEVNIKAR et al. [1] about the prevalence of pulmonary embolism (PE) in patients with coronavirus disease 2019 (COVID-19) at the time of hospital admission. In this prospective multicentre study, all consecutive adult outpatients that were hospitalised with a diagnosis of COVID-19 in three tertiary French hospitals between 15 April and 23 May 2020 underwent computed tomography pulmonary angiography (CTPA). Only patients with contraindications to the examination (mainly due to contraindication for iodinated contrast administration) were excluded. The strength of this study is that it finally provides precise information regarding the actual prevalence of PE in hospitalised COVID-19 patients. Over the past year, we have been bombarded almost daily with a seemingly infinite amount of data on the increased rate of venous thromboembolism (VTE) in COVID-19 patients, but all the studies available so far had the insurmountable flaw that CTPA was performed only in a minority of cases and mainly in patients with clinical suspicion of PE [2]. Another flaw of such previous studies was that CTPA was performed at various time-points during hospitalisation and, therefore, it was not possible to establish whether PE was an actual complication of COVID-19 or a consequence of the hospitalisation itself. In this scenario, the report of JEVNIKAR et al. [1] finally allows us to claim with substantiation that the prevalence of $\mathrm{PE}$ is high even at time of hospital admission in patients with COVID-19.

Nonetheless, we believe that this study, although important for the epidemiological reasons mentioned above, still does not provide a concrete contribution to the physicians that have to decide, on clinical grounds, whether to order or not order CTPA in patients with COVID-19. Certainly, the indiscriminate execution of CTPA cannot be the routine diagnostic regimen to use in these patients. We think that the time is upon us to establish a definite diagnostic algorithm for PE in COVID-19 patients. In the conclusion of their article, JEVNIKAR et al. [1] suggest to limit CTPA to patients who require supplemental oxygen and have high D-dimer concentrations. We wonder whether we should also use the pre-test probability scores recommended by international societies for diagnosing PE. In this context, we would be interesting to know how many of the patients of JeVNIKAR et al. [1] were at high risk of PE based on the Wells or Geneva rules, or in how many of them PE could be ruled out using the Pulmonary Embolism Rule Out Criteria (PERC) or the YEARS algorithm [3].

Another interesting point raised by the article of JEVNIKAR et al. [1] is that PE was more common among subjects with a longer time from the onset of COVID-19 symptoms to hospital admission. This is biologically plausible, since it is likely that these patients have been exposed for a longer time to risk factors for VTE, such as reduced mobility, acute infection and respiratory failure. For this reason, we believe that, in a study on the prevalence of PE on hospital admission, it is mandatory to know which treatment was administered to patients before hospitalisation, with particular attention to the use of anticoagulants. Indeed, although there is no general consensus on the use of anticoagulants as home treatment in COVID-19 patients, it is known that these medications are commonly prescribed. Obviously, their use at home might affect the prevalence of PE at the time of hospital admission.

\author{
Shareable abstract (@ERSpublications) \\ Further confirmation that COVID-19 patients are at high risk of venous thromboembolism \\ https://bit.ly/2OfPR5A
}

Cite this article as: Porfidia A, Pola E, Pola R. Prevalence of pulmonary embolism on hospital admission in COVID-19 patients: is there a role for pre-test probability scores and home treatment? Eur Respir J 2021; 58: 2100785 [DOI: 10.1183/13993003.00785-2021].
\end{abstract}


Angelo Porfidia $\oplus^{1}$, Enrico Pola ${ }^{2}$ and Roberto Pola $\oplus^{1}$

${ }^{1}$ Dept of Medicine, Fondazione Policlinico Universitario A. Gemelli IRCCS, Università Cattolica del Sacro Cuore, Rome, Italy. ${ }^{2}$ Primo Policlinico di Napoli, Ortopedia e Traumatologia, Università della Campania "Luigi Vanvitelli", Naples, Italy.

Corresponding author: Angelo Porfidia (angelo.porfidia@policlinicogemelli.it)

Conflict of interest: None declared.

\section{References}

1 Jevnikar M, Sanchez O, Chocron R, et al. Prevalence of pulmonary embolism in patients with COVID-19 at the time of hospital admission. Eur Respir J 2021; 58: 2100116.

2 Porfidia A, Valeriani E, Pola R, et al. Venous thromboembolism in patients with COVID-19: systematic review and meta-analysis. Thromb Res 2020; 196: 67-74.

3 Konstantinides SV, Meyer G, Becattini C, et al. 2019 ESC Guidelines for the diagnosis and management of acute pulmonary embolism developed in collaboration with the European Respiratory Society (ERS): The Task Force for the diagnosis and management of acute pulmonary embolism of the European Society of Cardiology (ESC). Eur Respir J 2019; 54: 1901647. 